\title{
Evidence of Toxoplasma gondii in Rodents from Bangladesh
}

\author{
Inge M. Krijger, ${ }^{1,2}$ Jan B.W.J. Cornelissen, ${ }^{3}$ Steven R. Belmain, ${ }^{4}$ \\ Rokeya Begum Shafali, ${ }^{5}$ and Bastiaan G. Meerburg ${ }^{1,6}$
}

\begin{abstract}
Rodents contribute to the life cycle of the protozoan parasite Toxoplasma gondii as an intermediate host and key prey animal of cats, the definitive host. As there is limited scientific knowledge available about the incidence and prevalence of $T$. gondii in commensal rodents in many Asian countries, we tested rodents from a commercial rice mill and eight local villages in Bangladesh for the presence of $T$. gondii DNA using rodent brain material preserved in ethanol. Overall, 10 of 296 (3.4\%) rodent samples tested positive for Toxoplasma DNA. Our results indicate that rodents present in food production and food storage facilities may carry $T$. gondii.
\end{abstract}

Keywords: Bandicota bengalensis, Mus musculus, Rattus rattus, T. gondii, food-borne disease, zoonosis

\section{Introduction}

F ELIDS ARE DEFINITIVE hosts for the protozoan parasite Toxoplasma gondii and are able to excrete $T$. gondii oocysts for several weeks after acute infection. The presence of excreted oocysts in the environment enables $T$. gondii to be taken up by numerous warm-blooded animal species acting as intermediate hosts. Humans become infected by ingesting undercooked food, contaminated water, soil, or unwashed fruits and vegetables (Dubey and Beattie 1988, Dubey 2004). Infection may also occur through infected organ transplants, or prenatally if a mother contracts toxoplasmosis while pregnant. In healthy persons, toxoplasmosis is usually asymptomatic. However, congenital infections can lead to numerous fetal manifestations or neurological or ocular problems later in life (Dubey and Jones 2008).

Rodents facilitate completion of the parasite life cycle as prey for cats. They may harbor $T$. gondii encysted within various body tissues, including muscle and brain tissue (Dubey et al. 1995). In many developing countries, cats are often kept around households, farms, granaries, and mills to control rodents. Hence, T. gondii transmission is possible (Brown and Khamphoukeo 2010). In such situations, environmental contamination with oocysts increases, facilitating more intermediate host infection. Rodents can also transmit T. gondii directly to humans as rodents are a common food source for cats in many countries (Khiem and Van Chien
2003, Suwannarong and Chapman 2014). In Thailand, seroprevalence of $4.6 \%$ of the collected rodents $(n=461)$ was found (Jittapalapong et al. 2011). Other studies have shown that rodent infections may be as high as $73 \%$, depending on rodent species, geographic region, and season (Tenter et al. 2000, Gotteland et al. 2014, Morand et al. 2015).

In humans, parts of Southeast Asia are areas of high seroprevalence (Pappas et al. 2009). In studies from 2002, seroprevalences in pregnant women from Asia ranged from 42 to 49\% (Borkakoty et al. 2007, Nissapatorn 2007, Torgerson and Mastroiacovo 2013). However, the situation varies per country and area as research from Vietnam reports a seroprevalence of $11.2 \%$ in pregnant women (Buchy et al. 2003), and research from 2012 reports a seroprevalence of $10.3 \%$ in Japanese pregnant women (Sakikawa et al. 2012). There is little information available from Bangladesh. In this article, we report the outcome of a study in 2016 and 2017 on the presence of $T$. gondii in rodents from Bangladesh using a qPCR on brain tissue stored in $98 \%$ ethanol. The potential effects of tissue storage time in ethanol have not been investigated for PCR detection of $T$. gondii.

\section{Materials and Methods}

From January 2016 to December 2017, rodents were trapped in 10 locations, of which 8 were local villages (Lakhshmipur, Manaharpur, Comalla, Kadamtoli, Maurali,

\footnotetext{
${ }^{1}$ Wageningen University and Research, Livestock Research, Wageningen, the Netherlands.

${ }^{2}$ Wageningen University and Research, Farm Technology Group, Wageningen, the Netherlands.

${ }^{3}$ Wageningen Bioveterinary Research, Lelystad, the Netherlands.

${ }^{4}$ Natural Resources Institute, University of Greenwich, Kent, United Kingdom.

${ }^{5}$ Association for Integrated Development-Comilla (AID-COMILLA), Comilla, Bangladesh.

${ }^{6}$ Dutch Pest and Wildlife Expertise Centre (KAD), Wageningen, the Netherlands.
} 
West-Maruali, Nagarkandi, and Baro Char) and 2 were rice mills in Comilla (Chittagong, all within $10 \mathrm{kms}$ of $23^{\circ} 27^{\prime} 23.0^{\prime \prime} \mathrm{N}$ $91^{\circ} 10^{\prime} 20.6^{\prime \prime} \mathrm{E}$, Bangladesh, Fig. 1). All villages are smallholder lowland farming communities and typically rely on rainfed rice production with limited irrigated rice production in some areas, with no discernible differences in ecology or cultural practices. The selected villages consisted of between 35 and 100 households.

There were no discernible patterns or changes in the ratio of species between these two habitats. Rodent trapping took place in the rice storage area of the selected households and mills and was conducted every 14 days, for a period of 3 months per location per year (so traps were placed 18 nights per location in 2016 and also in 2017). Each trapping session consisted of 3 consecutive days $(24 \mathrm{~h})$ with kill traps (Big snap-e; Kness, Albia, IA) and live cage traps (purchased on local Bangladesh markets). Traps were baited with banana and placed in the evening and checked for captures the next morning. Rodents trapped in live traps were euthanized by cervical dislocation. Each trapped animal was identified for species, gender, and maturity level, and thereafter dissected to collect brain tissue.

Owing to the lack of cold storage in rural areas, samples were stored in ethanol (98\%) for a period of 11 to a maximum of 35 months. Samples were shipped to a laboratory in the Netherlands for further testing. Randomly, one of the two brain halves was taken from each sample and put in $20 \mathrm{~mL}$ Dulbecco's phosphate-buffered saline (DPBS), which was refreshed after $4 \mathrm{~h}$ to rehydrate overnight. Twenty-four hours later, samples were homogenized in $1 \mathrm{~mL}$ fresh DPBS for $30 \mathrm{~s}$ with an ultra-turrax homogenizer. DNA was extracted from $250 \mu \mathrm{L}$ of the homogenated brain tissue with the DNeasy Blood \& Tissue kit (Qiagen GMBH, Hilden, Ger-

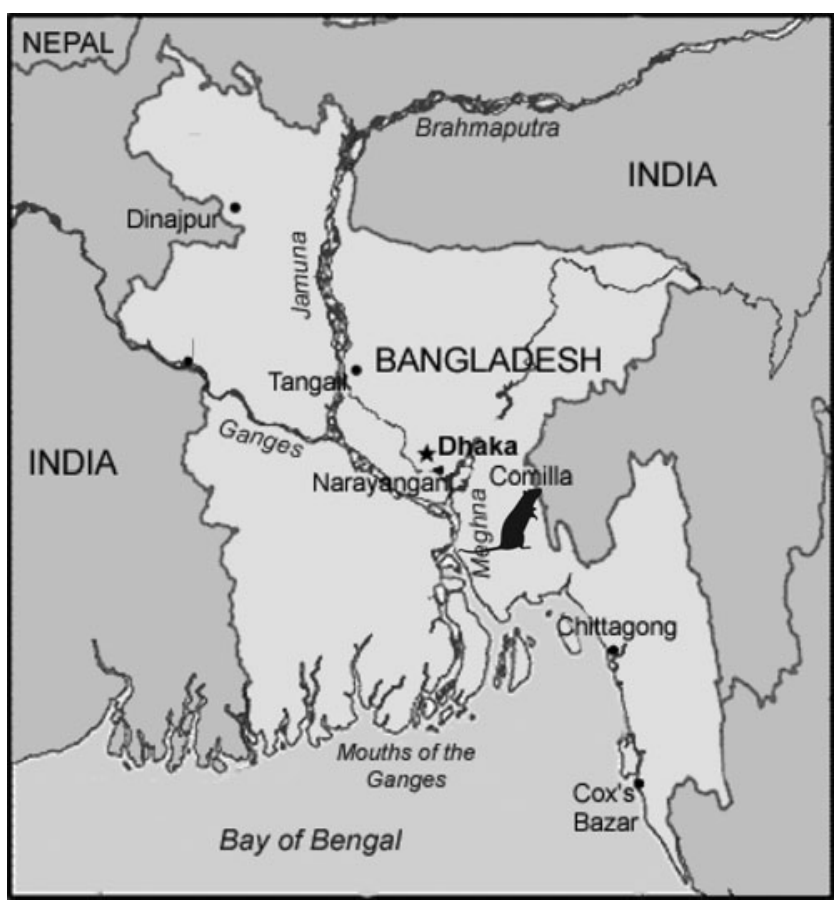

FIG. 1. Map of Bangladesh with the rat silhouette indicating the study site. many). Some adjustments to the manufacturer's protocol were made: glass beads (50-100 pc-diameter of $0.4 \mathrm{~mm}$ ) were added to each sample and vortexed $10 \mathrm{~min}$ at $1400 \mathrm{rpm}$ RT to facilitate lysis, wherein after lysis buffer was added according to the manufacturer's protocol. Samples were then incubated at $56^{\circ} \mathrm{C}$ for $2 \mathrm{~h}$, vortexed for $10 \mathrm{~min}$ at $1400 \mathrm{rpm}$ at $56^{\circ} \mathrm{C}$, and $1.5 \mu \mathrm{L} \mathrm{HCL} 35 \%$ was added together with ethanol for optimal DNA binding. Then, the manufacturer's protocol of the DNeasy Blood \& Tissue kit was followed. During the final step, samples were eluted in $50 \mu \mathrm{L}$ AE buffer. DNA samples were stored at $-20^{\circ} \mathrm{C}$ until tested by qPCR. Samples were tested in original DNA concentration and at a 1:5 dilution. Tachyzoite samples (T. gondii parasites, RH-type, starting concentration $3 \times 10^{\wedge} 8 / 50 \mu \mathrm{L}$ ) were used as a positive control in different concentrations to determine the limit of detection, and $\mathrm{H}_{2} \mathrm{O}$ was used as the negative control. To determine the test sensitivity, a series of 10-fold dilutions of tachyzoites starting from $3 \times 10^{\wedge} 7 / \mathrm{mL}$ were tested. DNA was tested for the $529 \mathrm{bp}$ fragment of $T$. gondii (Homan et al. 2000) by quantitative real-time PCR using a SyberGreen PCR Master Mix (Applied Biosystems, Foster City, CA) in an ABI 7500 Real-Time PCR system (PE Applied Biosystems). A final reaction volume of $25 \mu \mathrm{L}$ was used, consisting of $12.5 \mu \mathrm{L}$ of $2 \times$ QuantiTect SYBR Green PCR Master Mix, $10.5 \mu \mathrm{L}$ PCR grade water, $1 \mu \mathrm{L}(10 \mu \mathrm{M})$ of both primers (Toxoplasma amplification primers Tox-9 and Tox-11 [Reischl et al. 2003]), and $1 \mu \mathrm{L}$ of DNA template.

The PCR procedure started with an activation step of $10 \mathrm{~min}$ at $95^{\circ} \mathrm{C}$, followed by 50 amplification cycles consisting of $94^{\circ} \mathrm{C} / 15 \mathrm{~s}, 59^{\circ} \mathrm{C} / 30 \mathrm{~s}$, and $72^{\circ} \mathrm{C} / 30 \mathrm{~s}$. Dissociation was measured every $0.5^{\circ} \mathrm{C}$ and fluorescence was measured at the end of each cycle. A melting curve analysis was performed to check the specificity of the amplicons by their specific melting temperatures (Tm). All samples were tested with an analytic test sensitivity of three tachyzoites/mL (cycle threshold [Ct] $14.4=3 \times 10^{\wedge} 6$ tachyzoites/assay; $\mathrm{Ct}$ $31.4=3$ tachyzoites/assay). Samples were classified as positive when $\mathrm{Ct}$ values were $<37.5$ cycles, and with a Tm value between 81.9 and $83.5^{\circ} \mathrm{C}$.

\section{Results}

The overall trap success was $40.3 \%$ in the villages and $65 \%$ in the mills. In total, 296 commensal rodents were trapped of which 49 were Bandicota bengalensis, 8 Bandicota indica, 95 Mus musculus, 5 Mus terricolor, 15 Rattus exulans, and 124 Rattus rattus. Each animal was dissected and tested for the presence of $T$. gondii. The mean storage time of all samples was 21.3 months. Ten samples $(3.4 \%)$ were found positive (Table 1$)$, six of which were samples from $R$. rattus $(4.8 \%)$, two from $B$. bengalensis (4.08\%), one from $M$. terricolor (20.0\%), and one from M. musculus (1.05\%).

There was no statistically significant difference in prevalence between rodent species found $(p=0.18)$, and there were no differences in the positivity rates according to gender $(p=0.69)$. No differences in incidence were found over the trapping period or seasons.

\section{Discussion}

To our knowledge, no research on $T$. gondii infection in Bangladesh rodents has been carried out before. In this study, 
Table 1. Overview of the Species, Sample Storage Time, and Ct-Values of the Samples That Tested Positive With the Real-Time PCR Detection OF TOXOPLASMA GONDII

\begin{tabular}{|c|c|c|c|}
\hline Sample no. & Species & $\begin{array}{l}\text { Storage time } \\
\quad \text { (months) }\end{array}$ & Ct value \\
\hline 1 & Bandicota bengalensis & 21 & 35.71 \\
\hline 2 & Bandicota bengalensis & 17 & 34.37 \\
\hline 3 & Mus musculus & 18 & 33.17 \\
\hline 4 & Mus terricolor & 25 & 37.33 \\
\hline 5 & Rattus rattus & 28 & 22.72 \\
\hline 6 & Rattus rattus & 28 & 37.36 \\
\hline 7 & Rattus rattus & 16 & 36.57 \\
\hline 8 & Rattus rattus & 24 & 37.31 \\
\hline 9 & Rattus rattus & 23 & 24.28 \\
\hline 10 & Rattus rattus & 13 & 26.03 \\
\hline
\end{tabular}

$\mathrm{Ct}$, cycle threshold.

$3.4 \%$ of rodents trapped in or around food storage facilities tested positive for T. gondii DNA. This is in line with the results from Thai rodents in 2011, where a seroprevalence of 4.6\% $(n=461)$ was found (Jittapalapong et al. 2011). However, rodent infection rates can vary depending on the species researched, the location, and climate (Tenter et al. 2000, Gotteland et al. 2014, Morand et al. 2015). In Serbia, for example, a higher percentage of rodents were found to be positive; $10.4 \%$ of the 156 tested rodents (Rattus norvegicus and M. Musculus) were positive for Toxoplasma DNA using PCR (Vujanić et al. 2010). Research from the Netherlands showed $11.9 \%$ of 101 wild rodents and shrews positive for $T$. gondii DNA (Kijlstra et al. 2008), and a study from 2012 in the Netherlands found that $4 \%$ of rodents and shrews $(n=250)$ were positive using DNA detection (Meerburg et al. 2012), which again is more in line with the findings of our study in Bangladesh. In Brazil, wild feral rodents (Capybara [Hydrochaeris hydrochaeris]) were tested for $T$. gondii DNA and showed a prevalence of $15.4 \%(n=26)$ (Truppel et al. 2010). In China, a PCR study to detect $T$. gondii DNA showed $22.3 \%$ of $M$. musculus to be positive $(n=31)$ and $23.9 \%$ of the $R$. norvegicus trapped to be positive $(n=92)$ (Yan et al. 2014), which are relatively high percentages compared with other DNA studies on rodents.

Factors that could have influenced the difference in observed prevalences in the different rodent species from the selected trapping locations in Bangladesh could be the speciesspecific behavioral patterns, their ecology and ethology, and also the presence or absence of cats. None of the locations had cats as pets; however, there were stray cats around that could lead to rodent infection.

Reports of $T$. gondii infection in rodents from other Asian countries are mostly on $T$. gondii detection by serologic tests (Salibay and Claveria 2005, Jittapalapong et al. 2011, Herbreteau et al. 2012), but these have several disadvantages, that is, false negatives (Dubey et al. 1997). Thus, serology alone may be insufficient to determine rodent prevalence (Dubey and Frenkel 1998). PCR is more sensitive to detect $T$. gondii, but its use may be limited by cost and lack of experience (Nimir and Linn 2011). It is recommended to use either fresh samples or to store the samples at $\leq-20^{\circ} \mathrm{C}$ when carrying out PCR analyses because autolysis and/or degradation of DNA may occur when tissue samples are not immediately frozen or properly stored (Wastling and Mattsson 2003). In our study, it was not possible to use fresh or frozen samples and, therefore, brain tissue was preserved in ethanol.

The use of ethanol as a preservation method is applied in research on many other pathogens, for example, stool samples for research on the protozoan Giardia (Wilke and Robertson 2009), rodent ear biopsies and whole ticks for research on the bacterium Borrelia burgdorferi s.l., and rodent kidneys for research on Leptospira interrogans. The percentage of the ethanol is critical as ethanol drives out water from tissue and cells (thus dehydrates the tissue and so preserves DNA), therefore, it was decided to work with $98 \%$ ethanol. The potential effects of tissue storage time in ethanol have not been investigated for PCR detection of $T$. gondii. However, we found that isolation of $T$. gondii brain cysts after ethanol fixation is not possible by percoll gradients, which might have been a feasible DNA isolation procedure of the purified T. gondii cysts (Cornelissen et al. 1981).

Some of our samples were stored for 35 months in $98 \%$ ethanol, which might have led to prolonged dehydration and subsequent DNA degradation (Prendini et al. 2002). Furthermore, the high spread of the Tm values by amplicons found in the field samples gives an additional limitation of the long-term storage conditions in alcohol. It is possible that in this study, more animals harbored $T$. gondii DNA than the 10 animals found positive, due to degradation of sample quality. This is an important limitation of the study, thus the results need to be interpreted only as evidence for $T$. gondii infection. The results could underestimate the prevalence of $T$. gondii infection in Bangladesh rodents. However, to confirm this, several storage conditions should be compared (i.e., fresh samples, frozen storage, ethanol storage, formalin, and chemical matrices) (Lou et al. 2014). A suggestion for further research would be to also include DNA testing of heart material to minimize the chance of false negatives (Kijlstra et al. 2008).

Because $T$. gondii prevalence in rodents is influenced by environmental conditions (Meerburg et al. 2009) and could lead to infection of domestic cats, it is of essence that food stores and food processing facilities prevent rodent pests and limit the use of cats for rodent control. Further research is recommended to gain more insight into the prevalence of $T$. gondii in the rodent population across the food value chain in Bangladesh. A suggestion would be to study the presence of cats in the area, the prevalence of infection in cats, and the extent of rodent predation by cats. Other research that could add value to the current knowledge is researching the specific genotypes of $T$. gondii in Bangladesh to get a better understanding of the genetic population structure in Asia (Shwab et al. 2014, Chaichan et al. 2017).

\section{Acknowledgments}

The authors gratefully acknowledge the technical support provided by staff at the Association for Integrated DevelopmentComilla (AID-Comilla), with special thanks to Mr. Abul Kalam Azad, Mr. Abu Baker, Mr. Badruddoza Bappy, and Mr. Saiful Haque. The authors sincerely thank biosafety officer Henk J. Wisselink and staff at the rice mill for their cooperation. 


\section{Authors' Contributions}

I.M.K. set up the fieldwork, participated in part of the laboratory work, and wrote the article. J.B.W.J.C. designed and conducted the laboratory assays and finalized the Materials and Methods section of the article. S.R.B. and B.G.M. arranged the funding of the study. S.R.B. also participated in the writing of the article. B.G.M. participated in the study design and coordination and worked on the article. All authors read and approved the final article.

\section{Author Disclosure Statement}

No conflicting financial interests exist.

\section{References}

Borkakoty B, Borthakur A, Gohain M. Prevalence of Toxoplasma gondii infection amongst pregnant women in Assam, India. Indian J Med Microbiol 2007; 25:431-432.

Brown PR, Khamphoukeo K. Changes in farmers' knowledge, attitudes and practices after implementation of ecologicallybased rodent management in the uplands of Lao PDR. Crop Prot 2010; 29:577-582.

Buchy P, Follezou J, Lien T, An T, et al. Serological study of toxoplasmosis in Vietnam in a population of drug users (Ho Chi Minh city) and pregnant women (Nha Trang). Bull Soc Pathol Exot 2003; 96:46-47.

Chaichan P, Mercier A, Galal L, Mahittikorn A, et al. Geographical distribution of Toxoplasma gondii genotypes in Asia: A link with neighboring continents. Infect Genet Evol 2017; 53:227-238.

Cornelissen A, Overdulve J, Hoenderboom J. Separation of Isospora (Toxoplasma) gondii cysts and cystozoites from mouse brain tissue by continuous density-gradient centrifugation. Parasitology 1981; 83:103-108.

Dubey J. Toxoplasmosis-A waterborne zoonosis. Vet Parasitol 2004; 126:57-72.

Dubey J, Beattie C. Toxoplasmosis of Animals and Man. Boca Raton, FL: CRC Press, Inc., 1988.

Dubey J, Frenkel JK. Toxoplasmosis of rats: A review, with considerations of their value as an animal model and their possible role in epidemiology. Vet Parasitol 1998; 77:1-32.

Dubey J, Jones JL. Toxoplasma gondii infection in humans and animals in the United States. Int J Parasitol 2008; 38:12571278.

Dubey J, Shen S, Kwok O, Thulliez P. Toxoplasmosis in rats (Rattus norvegicus): Congenital transmission to first and second generation offspring and isolation of Toxoplasma gondii from seronegative rats. Parasitology 1997; 115:9-14.

Dubey J, Weigel RM, Siegel AM, Thulliez P, et al. Sources and reservoirs of Toxoplasma gondii infection on 47 swine farms in Illinois. J Parasitol 1995; 81:723-729.

Gotteland C, Chaval Y, Villena I, Galan M, et al. Species or local environment, what determines the infection of rodents by Toxoplasma gondii? Parasitology 2014; 141:259-268.

Herbreteau V, Bordes F, Jittapalapong S, Supputamongkol $\mathrm{Y}$, et al. Rodent-borne diseases in Thailand: Targeting rodent carriers and risky habitats. Infect Ecol Epidemiol 2012; 2:5.

Homan W, Vercammen M, De Braekeleer J, Verschueren H. Identification of a 200-to 300-fold repetitive $529 \mathrm{bp}$ DNA fragment in Toxoplasma gondii, and its use for diagnostic and quantitative PCR. Int J Parasitol 2000; 30:69-75.
Jittapalapong S, Sarataphan N, Maruyama S, Hugot J-P, et al. Toxoplasmosis in rodents: Ecological survey and first evidences in Thailand. Vector Borne Zoonotic Dis 2011; 11: 231-237.

Khiem NT, Van Chien H. Market study of meat from field rats in the Mekong Delta. In: Singleton G, Hinds L, Krebs C, Spratt D, eds. Rats, Mice and People: Rodent Biology and Management. Canberra: Australian Centre for International Agricultural Research, 2003:543-547.

Kijlstra A, Meerburg B, Cornelissen J, De Craeye S, et al. The role of rodents and shrews in the transmission of Toxoplasma gondii to pigs. Vet Parasitol 2008; 156:183-190.

Lou JJ, Mirsadraei L, Sanchez DE, Wilson RW, et al. A review of room temperature storage of biospecimen tissue and nucleic acids for anatomic pathology laboratories and biorepositories. Clin Biochem 2014; 47:267-273.

Meerburg BG, De Craeye S, Dierick K, Kijlstra A. Neospora caninum and Toxoplasma gondii in brain tissue of feral rodents and insectivores caught on farms in the Netherlands. Vet Parasitol 2012; 184:317-320.

Meerburg BG, Singleton GR, Kijlstra A. Rodent-borne diseases and their risks for public health. Crit Rev Microbiol 2009; 35: 221-70.

Morand S, Bordes F, Blasdell K, Pilosof S, et al. Assessing the distribution of disease-bearing rodents in human-modified tropical landscapes. J Appl Ecol 2015; 52:784-794.

Nimir AR, Linn TC. Detection of toxoplasmosis in environmental samples at a wet market of a capital city centre. Acta Med (Hradec Kralove) 2011; 54:107-110.

Nissapatorn V. Toxoplasmosis: A silent threat in Southeast Asia. Res J Parasitol 2007; 2:1-12.

Pappas G, Roussos N, Falagas ME. Toxoplasmosis snapshots: Global status of Toxoplasma gondii seroprevalence and implications for pregnancy and congenital toxoplasmosis. Int $\mathbf{J}$ Parasitol 2009; 39:1385-1394.

Prendini L, Hanner R, DeSalle R. Obtaining, storing and archiving specimens and tissue samples for use in molecular studies. In: DeSalle R, Giribet G, Wheeler W, eds. Techniques in Molecular Systematics and Evolution. Berlin: Springer, 2002:176-248.

Reischl U, Bretagne S, Krüger D, Ernault P, et al. Comparison of two DNA targets for the diagnosis of Toxoplasmosis by real-time PCR using fluorescence resonance energy transfer hybridization probes. BMC Infect Dis 2003; 3:7.

Sakikawa M, Noda S, Hanaoka M, Nakayama H, et al. AntiToxoplasma antibody prevalence, primary infection rate, and risk factors in a study of Toxoplasmosis in 4,466 pregnant women in Japan. Clin Vaccine Immunol 2012; 19: 365-367.

Salibay CC, Claveria FG. Serologic detection of Toxoplasma gondii infection in Rattus spp collected from three different sites in Dasmariñas, Cavite, Philippines. Southeast Asian J Trop Med Public Health 2005; 36:46-49.

Shwab EK, Zhu X-Q, Majumdar D, Pena HFJ, et al. Geographical patterns of Toxoplasma gondii genetic diversity revealed by multilocus PCR-RFLP genotyping. Parasitology 2014; 141:453-461.

Suwannarong K, Chapman RS. Rodent consumption in Khon Kaen Province, Thailand. Southeast Asian J Trop Med Public Health 2014; 45:1209-20.

Tenter AM, Heckeroth AR, Weiss LM. Toxoplasma gondii: From animals to humans. Int J Parasitol 2000; 30:12171258. 
Torgerson PR, Mastroiacovo P. The global burden of congenital toxoplasmosis: A systematic review. Bull World Health Org 2013; 91:501-508.

Truppel JH, Reifur L, Montiani-Ferreira F, Lange RR, et al. Toxoplasma gondii in Capybara (Hydrochaeris hydrochaeris) antibodies and DNA detected by IFAT and PCR. Parasitol Res 2010; 107:141-146.

Vujanić M, Ivović V, Kataranovski M, Nikolić A, et al. Toxoplasmosis in naturally infected rodents in Belgrade, Serbia. Vector Borne Zoonotic Dis 2010; 11:1209-1211.

Wastling JM, Mattsson JG. Detection of Toxoplasma gondii. In: Sachse K, Frey J, eds. PCR Detection of Microbial Pathogens. Totowa, NJ: Humana Press, 2003:289-298.

Wilke H, Robertson LJ. Preservation of Giardia cysts in stool samples for subsequent PCR analysis. J Microbiol Methods 2009; 78:292-296.
Yan C, Liang L-J, Zhang B-B, Lou Z-L, et al. Prevalence and genotyping of Toxoplasma gondii in naturally-infected synanthropic rats (Rattus norvegicus) and mice (Mus musculus) in eastern China. Parasit Vectors 2014; 7:591.

Address correspondence to: Inge $M$. Krijger Wageningen University and Research Livestock Research PO Box 338, 6700 AH Wageningen The Netherlands

E-mail: inge.krijger@wur.nl 